\title{
Uso e ocupação do solo do município de novo progresso no Estado do Pará-Brasil
}

\author{
Land use and occupancy in the municipality of new progress in the State of Pará-Brazil \\ Uso y ocupación de la tierra en el municipio de novo progress en el Estado de Pará-Brasil
}

Recebido: 18/01/2021 | Revisado: 20/01/2021 | Aceito: 22/01/2021 | Publicado: 28/01/2021

\author{
Raimara Reis do Rosário \\ ORCID: https://orcid.org/0000-0003-0502-2420 \\ Universidade Federal Rural da Amazônia, Brasil \\ E-mail: raimara.reis.rr@gmail.com \\ Mateus Trindade Barbosa \\ ORCID: https://orcid.org/0000-0003-0570-5475 \\ Universidade Federal Rural da Amazônia, Brasil \\ E-mail: mateustrindade3000@gmail.com \\ Francimary da Silva Carneiro \\ ORCID: https://orcid.org/0000-0002-1693-8779 \\ Universidade Federal Rural da Amazônia, Brasil \\ E-mail: francimarycarneiro@gmail.com \\ Merilene do Socorro Silva Costa \\ ORCID: https://orcid.org/0000-0002-9299-6786 \\ Universidade Federal Rural da Amazônia, Brasil \\ E-mail: merilene@hotmail.com
}

\begin{abstract}
Resumo
O objetivo foi analisar o processo de uso e ocupação do solo do município de Novo Progresso no Estado do Pará, interligando-o com as atividades de maior importância econômica desenvolvidas nesta região. Utilizou-se o shapefile de limite do município de Novo Progresso na plataforma online Google Earth Engine (GEE), que disponibilizou um mosaico de imagens orbitais, do satélite Landsat-8/OLI-TIRS, referentes ao ano de 2019. O processo de classificação foi feito a partir do Code Editor do GEE, utilizando um Índice espectral de vegetação para auxiliar a classificação (Normalized Difference Vegetation Index - NDVI). Foi utilizado o Software QGis 3.10.6 para elaborar os mapas de localização do município e o de classificação de uso e cobertura do solo. Os dados foram tabulados em planilhas para determinar as taxas de crescimento do período analisado. Para realizar a avaliação da confiabilidade da classificação foi utilizado o método de Exatidão Global e o Índice Kappa. Foi possível identificar que no ano de 2019, houve a incidência de 3.064.396,65 ha $(80,3 \%)$ de floresta densa, uma área de 496.104,07 ha (13,0\%) com solo exposto, $248.052,03$ ha $(6,5 \%)$ de floresta secundária, e apenas $7.632,37$ ha $(0,2 \%)$ com predominância de hidrografia, totalizando uma área de $3.816 .185,13$ ha. As áreas que encontram-se com o solo exposto não estão diretamente relacionadas com o crescimento populacional, mas sim a forma como é estabelecido o uso do solo, com base nas principais atividades desenvolvidas na região considerando que a lógica produtiva ocorre de forma desordenada, não respeitando os critérios de desenvolvimento sustentável.
\end{abstract}

Palavras-chave: Geotecnologias; Ocupação territorial; Sudoeste paraense.

\begin{abstract}
The objective was to analyze the process of land use and occupation in the municipality of Novo Progresso in the State of Pará, linking it with the most economically important activities developed in this region. The limit shapefile of the municipality of Novo Progresso was used on the Google Earth Engine (GEE) online platform, which provided a mosaic of orbital images, from the Landsat-8 / OLI-TIRS satellite, for the year 2019. The classification process was made from the GEE Code Editor, using a spectral index of vegetation to aid classification (Normalized Difference Vegetation Index - NDVI). Software QGis 3.10.6 was used to prepare maps of the municipality's location and the land use and land cover classification maps. The data were tabulated in spreadsheets to determine the growth rates of the analyzed period. In order to assess the reliability of the classification, the Global Accuracy method and the Kappa Index were used. It was possible to identify that in 2019 , there was an incidence of $3,064,396.65$ ha $(80.3 \%)$ of dense forest, an area of $496,104.07$ ha $(13.0 \%)$ with exposed soil, $248,052.03$ ha $(6.5 \%)$ of secondary forest, and only $7,632.37$ ha $(0.2 \%)$ with predominance of hydrography, totaling an area of $3,816,185.13$ ha. The areas that are exposed to the exposed soil are not directly related to population growth, but rather to the way in which land use is established, based on the main activities developed in the region considering that the productive logic occurs in a disordered way, not respecting the criteria of sustainable development.
\end{abstract}

Keyword: Geotechnologies; Territorial occupation; Southwest Pará. 


\section{Resumen}

El objetivo fue analizar el proceso de uso y ocupación del suelo en el municipio de Novo Progresso en el Estado de Pará, vinculándolo con las actividades económicamente más importantes desarrolladas en esta región. Se utilizó el shapefile límite del municipio de Novo Progresso en la plataforma en línea Google Earth Engine (GEE), que brindó un mosaico de imágenes orbitales, del satélite Landsat-8 / OLI-TIRS, para el año 2019. El proceso de clasificación se realizó a partir del Editor de código GEE, utilizando un índice espectral de vegetación para ayudar a la clasificación (Índice de vegetación de diferencia normalizada - NDVI). Se utilizó el software QGis 3.10.6 para preparar mapas de la ubicación del municipio y los mapas de clasificación de uso y cobertura del suelo. Los datos se tabularon en hojas de cálculo para determinar las tasas de crecimiento del período analizado. Para evaluar la confiabilidad de la clasificación se utilizó el método de Exactitud Global y el Îndice Kappa. Se pudo identificar que en 2019, hubo una incidencia de 3,064,396.65 ha (80.3\%) de bosque denso, un área de 496,104.07 ha (13.0\%) con suelo expuesto, $248,052.03$ ha $(6,5 \%)$ de bosque secundario, y solo $7.632,37$ ha $(0,2 \%)$ con predominio de la hidrografía, totalizando una superficie de 3.816.185,13 ha. Las áreas que se encuentran expuestas al suelo expuesto no están directamente relacionadas con el crecimiento poblacional, sino más bien con la forma en que se establece el uso del suelo, con base en las principales actividades desarrolladas en la región considerando que la lógica productiva se da de manera desordenada, no respetando los criterios de desarrollo sostenible.

Palabra clave: Geotecnologías; Ocupación territorial; Suroeste de Pará.

\section{Introdução}

O Brasil ainda é um dos países remanescentes do mundo que permanecem agregando novos territórios sem respeitar as populações nativas da região amazônica, provocando segregação entre a população, principalmente, as que pertencem a classes menos favorecidas, e causando transformações diversas tanto no meio rural quanto no urbano. Esse evento, intensificado pelos acontecimentos do cenário atual, apresentando a necessidade socioeconômica e, pelo outro ponto de vista, as consequências ambientais, torna difícil o encontro de um modelo que mantenha o equilíbrio entre ser socialmente justo e ambientalmente correto (Passos, 2017).

De acordo com Araújo (2015), tais mudanças que estão ocorrendo na região amazônica são consequência de intervenções antrópicas que tiveram início desde a edificação de rodovias e assentamentos com estruturas caóticas à exploração mineral e madeireira, desencadeando o crescimento da fronteira agrícola, trazendo consigo sérios problemas populacionais, além de afetar diretamente a biodiversidade. No entanto, o motivo mais relevante para o crescimento do desmatamento é a ausência de uma política mais justa e rígida para controlar o avanço populacional e a exploração desenfreada da diversidade biológica.

É importante ressaltar que entre o período de 1879 e 1912, o ápice da exploração da borracha, foi um dos acontecimentos que mais marcaram o processo de expansão da ocupação da região amazônica, além de representar o avanço ocorrido em meados do século XVIII (Rebello \& Homma, 2017). A partir da década de 60, sob o comando de militares, a Amazônia tornou-se alvo de iniciativas estatais que visavam iniciar uma nova etapa de programas voltados ao desenvolvimento e exploração econômica da Amazônia. A construção da BR-163, trecho que interliga a região de Cuiabá/MT e Santarém/PA, foi construída com o intuito de desenvolver a Amazônia e até mesmo o Brasil, porém a maioria dos trabalhadores que chegaram à região com o apoio financeiro do Governo Federal, não encontram no cenário atual o que havia sido prometido no início da construção do que seria o novo trecho de colonização (Passos, 2017).

O município de Novo Progresso é constituinte desse cenário de ocupação e desenvolvimento estabelecido, tendo vivenciado diversas fases na sua economia, transitando pelo período da borracha, extração de ouro, madeira e nos dias atuais, possui uma economia dirigida pela agropecuária, sendo destaque o setor da pecuária, tendo em vista que é o responsável por uma parcela significativa do seu desenvolvimento em função das relações econômicas com o estado do Mato Grosso dentre outros municípios da região (Araújo, 2015). No entanto, o acentuado processo de ocupação desordenada procedeu na devastação de áreas extensas na região sul do Pará, tendo como principais causadores o setor da pecuária e exploração madeireira (Castro, 2005). 
Considerada como uma das ferramentas mais importantes para a execução de análises ambientais, as geotecnologias (Sensoriamento Remoto, Sistemas de Informações Geográficas, GPS, etc.) consistem em um conjunto de tecnologias para coleta, processamento, análise e oferta de informações com referência geográfica (Junior, et al., 2017), que auxiliam na produção de mapas, sendo este uma ferramenta crucial ao planejamento técnico-científico, norteando a tomada de decisão referente a utilização consciente da biodiversidade e da cobertura vegetal para unidades territoriais distintas (Ferreira, et al., 2016; Pereira, et al.; 2020). Além disso, as geotecnologias proporcionam maior agilidade e versatilidade, propagação das informações de maneira mais econômica e com maior agilidade (Junior, et al., 2017).

O objetivo deste estudo é analisar, com o auxílio de produtos e técnicas de sensoriamento remoto associado aos recursos de SIG, o processo de uso e ocupação do solo do município de Novo Progresso no Estado do Pará, interligando-o com as atividades de maior importância econômica desenvolvidas nesta região.

\section{Metodologia}

O presente estudo abrange o município de Novo Progresso inserido na Mesorregião do Sudoeste Paraense e na Microrregião de Itaituba. Sua localização corresponde às coordenadas geográficas $65^{\circ} 08^{\prime} 30^{\prime \prime} \mathrm{S}$ e $55^{\circ} 24^{\prime} 00^{\prime \prime} \mathrm{W}$ de Greenwich, com distância de aproximadamente 987 km da capital Belém (Silva, 2019).

A metodologia é de natureza qualiquantitativa (Pereira, et al.,2018), foi utilizado um mosaico de imagens orbitais de média resolução espacial referentes ao ano de 2019, o satélite utilizado foi o Landsat-8/OLI-TIRS disponibilizadas no Google Earth Engine (GEE), visto que esta é uma plataforma online que contém uma biblioteca de imagens que é alimentada constantemente e que oferece instrumentos computacionais para monitoramento da superfície da terra (Gorelick, et al., 2017). A partir do Shapefile de limite do município de Novo Progresso que é a área de estudo equivalente a uma área de 3.816.185,13 ha, foi feita a classificação de uso e cobertura do solo. O processo de classificação foi feito a partir do Code Editor do GEE desenvolvido em linguagem de programação JavaScript. Dessa forma, foi utilizado um Índice espectral de vegetação para auxiliar a classificação (Normalized Difference Vegetation Index - NDVI). 
Figura 1. Mapa de localização do Município de Novo Progresso - PA (2019).

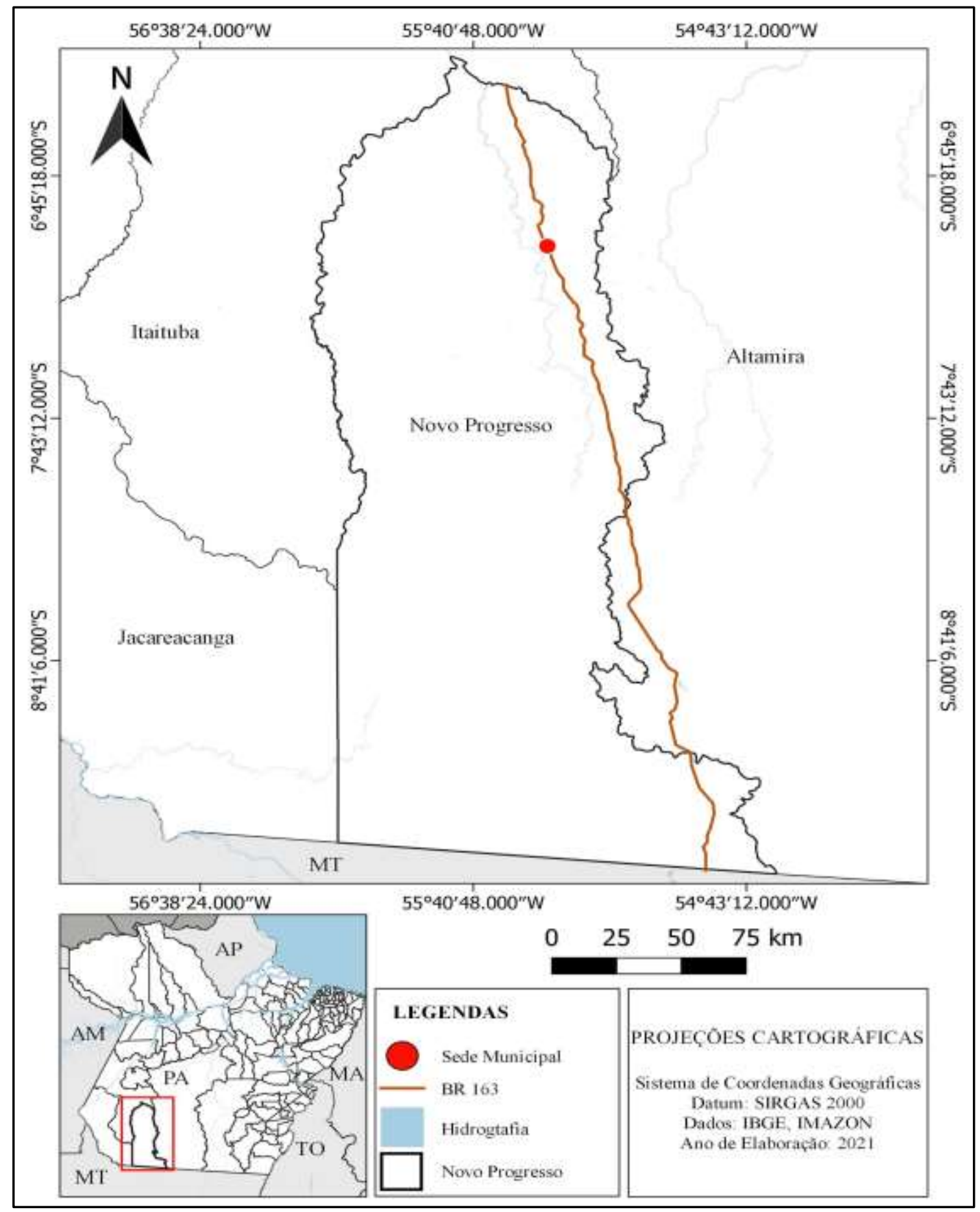

Fonte: Autores (2021).

A avaliação da confiabilidade da classificação foi feita a partir de uma matriz de confusão para calcular a concordância (Exatidão Global e o Índice Kappa). É importante ressaltar que não foram feitas visitas em campo. O resultado está expresso na (Figura 2) e na (Tabela 2).

A elaboração dos mapas georreferenciados de localização do município e de classificação de uso e cobertura do solo do Município de Novo Progresso ocorreu através do Software QGis 3.10.6 e do uso da base cartográfica vetorial disponibilizada pelo IBGE. 
Após a obtenção dos dados, com o auxílio do software Microsoft Excel@, as informações sobre as classes de uso e ocupação do solo em Novo Progresso, foram tabuladas em planilhas para o tratamento por meio de ferramentas estatísticas oferecidas pelo programa, para determinar as taxas de crescimento do período analisado.

\section{Resultados e Discussão}

\section{Dinâmica de uso e ocupação do solo do município de Novo Progresso (PA)}

Durante o processo de caracterização e identificação do uso e cobertura do solo do município, foi possível identificar quatro tipos de feições, sendo vegetação densa, vegetação secundária, solo exposto e hidrografia. Com o intuito de representar tais feições, foi confeccionado um mapa temático das áreas classificadas referentes ao ano de 2019, mostrando como a disposição dessas feições altera significativamente a paisagem da região e o modo como os diferentes agentes da biodiversidade interagem entre si no ambiente, podendo ser observado na Figura 2.

A Floresta Equatorial pode ser caracterizada nessa pesquisa como vegetação densa e está relacionada a áreas que ainda não passaram de forma direta pelo processo de antropização. A Vegetação Secundária é o resultado de áreas que apresentam uma mudança progressiva em uma comunidade ecológica, evidenciando a influência da pecuária e da exploração madeireira no processo de sucessão florestal. As áreas identificadas como solo exposto retratam o avanço da população e da tecnologia sobre regiões de interesse econômico, estando diretamente relacionada aos métodos utilizados para preparar o solo para o cultivo e manejar os animais de produção, essa classe está integrada às áreas urbanas. Por fim, as áreas classificadas como água, foram identificadas em conformidade com a drenagem presente na área de estudo (Ferreira, et al., 2018).

A veracidade da classificação pode ser observada na Tabela 1, na qual aponta um resultado de exatidão global acima de $90 \%$, mostrando-se excelente, porém o índice Kappa de 0,70 denotando neste, um resultado regular para a análise estatística. 
Figura 2. Mapa de uso e ocupação do solo do Município de Novo Progresso - PA (2019).

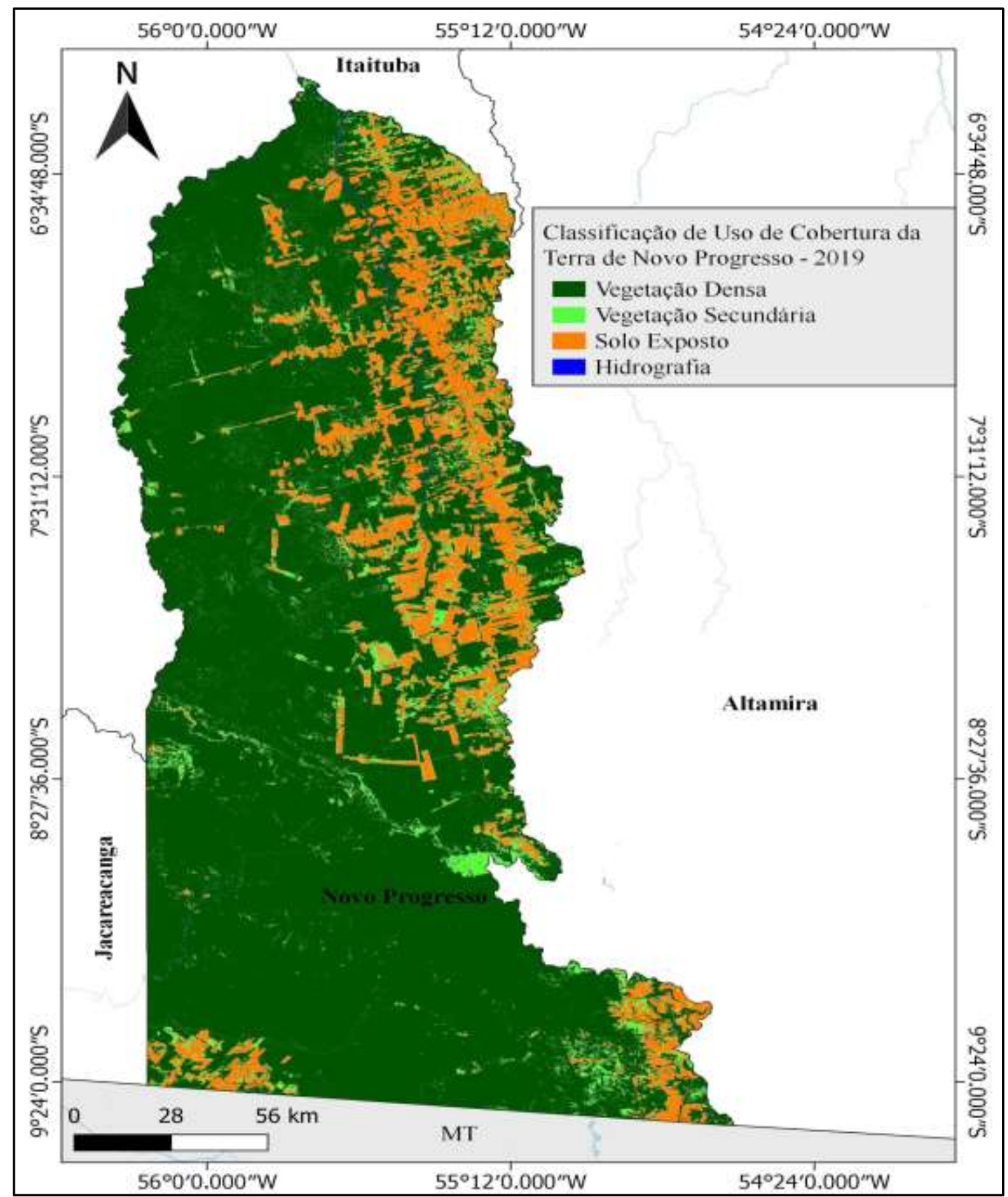

Fonte: Autores (2021).

Tabela 1. Veracidade do mapeamento de uso e cobertura do solo no Município de Novo Progresso - PA em 2019.

\begin{tabular}{ccc}
\hline Ano & Exatidão Global & Índice Kappa \\
\hline $\mathbf{2 0 1 9}$ & $90 \%$ & $0,70-$ Regular \\
\hline
\end{tabular}

Fonte: Dados da pesquisa (2020).

A partir do mapeamento de uso e cobertura do solo de Novo Progresso, no ano de 2019, observou-se as diferentes variações de classes de ocupação e uso do solo na região, estando os dados dispostos na tabela a seguir (Tabela 2). 
Tabela 2. Área (ha) e Participação Relativa (\%) das classes de uso do solo no Município de Novo Progresso - PA em 2019.

\begin{tabular}{ccc}
\hline Classe & Área (ha) & Participação Relativa (\%) \\
\hline Vegetação Densa & $3.064 .396,65$ & $80,30 \%$ \\
Solo Exposto & $496.104,07$ & $13,00 \%$ \\
Vegetação Secundária & $248.052,03$ & $6,50 \%$ \\
Hidrografia & & \\
Total & $7.632,37$ & $0,20 \%$ \\
\hline
\end{tabular}

Fonte: Autores (2021).

Diante dos dados apresentados, em 2019 (Figura 2 e Tabela 2) identificou-se a incidência de 3.064.396,65 ha (80,3\%) de floresta densa, uma área de 496.104,07 ha (13,0\%) com solo exposto, 248.052,03 ha (6,5\%) de floresta secundária, e apenas 7.632,37 ha (0,2\%) com predominância de hidrografia, totalizando uma área de 3.816.185,13 ha. Esses dados mostram que apesar da pecuária ser uma das principais atividades dessa mesorregião, cerca de 80,3\% da área total do município ainda encontra-se coberta por vegetação, apresentando um nível significativo de preservação das áreas constituídas por floresta.

Ao observar o mapa (Figura 2) é perceptível que a maior ocorrência de áreas de solo exposto encontra-se próxima a BR-163, principal via que interliga as regiões de Cuiabá/MT e Santarém/PA, auxiliando no escoamento da produção agropecuária, principalmente a pecuária, responsável por uma grande parcela do desenvolvimento da região sudoeste do estado. No entanto, observando as áreas mais afastadas dessa importante rodovia é notória a predominância de vegetação, corroborando com Costa et al. (2017), que a maior parte dos focos de queimadas incide nas proximidades da rodovia BR-163, mostrando que há uma menor ocorrência de desmatamento a medida que essas áreas estiverem mais afastadas das estradas. De acordo com Fearnside (2002) o desmatamento e as queimadas na Região Amazônica são provocados em função da atividade agropecuária. Deste modo, compreende-se que as áreas de solo exposto ao entorno da área de influência da rodovia, podem vir a sofrer a ação do fogo, sendo este o método mais utilizado para manejar pastagens e limpar as áreas destinadas à agricultura (Costa, et al., 2017).

Com o passar dos anos, a construção de estradas na Região Amazônica ainda é considerado um fator significativo para o crescimento do processo de ocupação territorial, tendo como consequência, a perda da cobertura florestal. De acordo com estudos, os desflorestamentos apresentam maior concentração no trecho que corresponde aos primeiros $5 \mathrm{~km}$ ao longo das estradas e vicinais (Lameira, et al., 2010; Xaud \& Epiphanio, 2015). Desse modo, as estradas tornaram-se um meio importante para realizar a exploração de recursos naturais, principalmente quando as atividades estavam relacionadas às atividades agropecuárias e minerais (Fearnside, 2015).

Ao analisar essa região, deve-se considerar que a mesma estava inserida em um plano de desenvolvimento econômico, elaborado em determinados governos, que visava integrar a Amazônia a outras regiões do país utilizando políticas de interiorização (Araújo, 2015). A construção de estradas, como por exemplo, a rodovia BR 163 (Cuiabá/MT - Santarém/PA), promoveu um acentuado fluxo de agricultores migrando, de inúmeras regiões do território brasileiro para o norte do país durante as décadas de 1970 e 1980, influenciando diretamente a criação e desenvolvimento do município de Novo Progresso (Margarit, 2013). No entanto, a implementação de tais políticas alcançaram resultados distintos, como o aumento da retirada da cobertura florestal, o crescimento e o surgimento desordenado de cidades, conflitos agrários, dentre outros (Becker, 2005; Rego \& Freitas, 2015). 


\section{Atividades Econômicas}

Considerando o contexto amazônico, o termo desenvolvimento apresenta um significado que relaciona-se com os métodos utilizados pelos indivíduos para ocupar as regiões associadas a políticas públicas intervencionistas, ações da iniciativa privada e exploração dos recursos naturais (Shuber, 2015).

Diante disso, o processo de territorialização da Região do Tapajós iniciou-se em meados dos séculos XVIII e XIX, nos municípios de Aveiro e Itaituba, estando associadas à extração e comércio das "drogas do sertão", missões religiosas e anos depois à economia da borracha (Shuber, 2015).

A descoberta de diversas jazidas de ouro, provocou uma intensa transformação econômica e social na região, devido à prática da atividade garimpeira, que influenciou o modo de vida da população de alguns municípios como Jacareacanga, Itaituba e Novo Progresso, que durante a década de 60 era denominado de Progresso (Araújo, 2015).

Durante o ano de 1990 a prática garimpeira começou a retroceder na cidade de Itaituba, sendo a partir deste originado o município de Novo Progresso, provocando uma crise tanto econômica quanto social, ocasionando uma intensa diversificação da economia local, principalmente no que se refere ao extrativismo e a pecuária de corte. Os lucros advindos da atividade garimpeira, foram de extrema importância para auxiliar no desenvolvimento da economia agrícola, sendo direcionados principalmente para as fazendas. Ao associar tais investimentos a elevadas taxas de transporte de mercadoria para a região, culminou no crescimento da atividade pecuária na região oeste do estado, tornando-se uma prática lucrativa, que estimulou o crescimento econômico de uma das principais regiões responsáveis pela exportação de carne e grãos do país (Shuber, 2015).

Atualmente, a economia do município de Novo Progresso é baseada na Pecuária, Agricultura, Extrativismo Mineral (Ouro, estanho, diamante, ametista, turmalina, topázio e calcário), Extrativismo Vegetal (castanha-do-pará, açaí, madeira, palmito e carvão vegetal), e Estabelecimentos comerciais (Ferreira, 2003). Desse modo, o município apresenta uma diversa variabilidade em suas atividades econômicas, que influenciam no modo de uso e ocupação do solo. De acordo com o IBGE (2019), Novo Progresso, ocupa a nona posição do maior rebanho de gado do Pará, contendo 618 mil cabeças em 2017, além de uma área de cultivo de soja que apresentou um aumento de 17 mil hectares entre o período de 2013 e 2017 (IBGE, 2019).

\section{Agricultura}

O processo de colonização que iniciou-se com os governos na década de 70, contribuiu com o início das atividades de exploração, no entanto, as áreas desflorestadas eram menores, pois a agricultura era familiar e requeria pequenas áreas, tendo em vista que a população não possuía verba suficiente para investir em suas produções. Porém, os aspectos físicos e a dinâmica econômica da região tornou-se um grande atrativo para empresários estabelecerem seus grandes latifúndios, concentrando as terras nas mãos dos detentores de maior poder aquisitivo, levando os pequenos produtores a evadirem da região que ocupam, vendendo ou abandonando suas propriedades, migrando para os grandes centros urbanos, caracterizando o processo conhecido como Êxodo Rural. Desse modo, mesmo a Agricultura promovendo o crescimento econômico e populacional da região, vale ressaltar que a mesma ultrapassa um extenso limite de áreas para implantar suas plantações que geram emprego, renda e áreas ausentes de cobertura vegetal (Gavlak, et al., 2011).

O IBGE, com base na Produção Agrícola Municipal de 2019, apresenta dados que mostram a diversidade da produção agrícola no município. A respeito da produção em lavoura temporária, os dados apontam como principais produtos cultivados em Novo Progresso, a Soja em grão em 12.500 ha (41.250 toneladas), o Milho em grão em 4.000 ha (18.000 toneladas), o Arroz em casca em 2.000 ha (4.800 toneladas) e a Mandioca em 1.000 ha (13.000 toneladas) (IBGE, 2019).

Em relação a produção em lavoura caracterizada como permanente, os principais produtos cultivados no município, são a banana que apresentou uma área colhida de 60 ha (420 toneladas), Coco-da-baía em 30 (120 toneladas), o Açaí em 26 ha (130 toneladas), a Laranja em 20 ha (220 toneladas) e o Limão com 15 ha (225 toneladas) (IBGE, 2019). 
Com o passar dos anos, a Agricultura, apresentou uma redução em seus valores produzidos, enquanto a Pecuária continua em constante ascendência, sendo perceptível as mudanças recorrentes no modo de utilização da terra. Este fato, devese a forma como a Agricultura é mais dependente de determinados fatores para realizar suas atividades diárias no campo, como o clima, mão de obra, insumos e transporte, tornando-a menos viável que a Pecuária, que apesar desta depender de alguns dos mesmos fatores da agricultura, consegue se tornar menos dispendiosa e exigente para seu desenvolvimento (Araújo, 2015).

\section{Pecuária}

De acordo com os dados disponibilizados pelo Instituto Brasileiro de Geografia e Estatística (IBGE), a pecuária é a principal atividade que representa o uso do solo, no âmbito agrícola desta mesorregião (IBGE, 2006). Essa atividade é movimentada por pecuaristas de diferentes níveis, tendo destaque os de médio e grande porte, responsáveis por uma parcela significativa dos desmatamentos recorrentes na região, enquanto que os pequenos proprietários trabalham fornecendo mão de obra ou intermediando a ocupação temporária de terras, enquanto não conseguem legitimar a posse da terra (Margulis, 2003).

Segundo Rivero, et al (2009), a região Amazônica possui características que continuarão motivando indivíduos a investir na criação de gado, tendo em vista que a pecuária não exige altos níveis de investimento, não há grandes exigências para o preparo do solo e possui restrições limitadas relacionadas a relevo e a áreas ausentes de troncos em florestas desmatadas em um curto período de tempo. Além disso, se faz necessário ressaltar a disponibilidade de terras com preços acessíveis e características que promovem uma maior produtividade das pastagens, como pluviosidade, temperatura e umidade do ar (Margulis, 2003).

Em 2019, o IBGE, disponibilizou dados dos principais efetivos de rebanho do Município de Novo Progresso, tendo como destaque os galináceos com um total de 55.380 cabeças e os bovinos com 625.979 cabeças, sendo este último o principal produto comercializado, tendo em vista que a pecuária é a atividade de maior destaque na região, tanto para a produção de gado de corte como a atividade leiteira, em função da proximidade com abatedouros no Mato Grosso e laticínios em Novo Progresso. A comercialização do gado de corte não se limita ao estado do Mato Grosso, ocorre também nas comunidades urbanas situadas ao longo da BR-163, no trecho correspondente ao estado do Pará, enquanto que a produção leiteira é comercializada nas comunidades mais próximas ou na própria comunidade onde o produto é produzido (Asta, et al., 2011).

De acordo com os estudos de Alves et al. (2010), os elevados índices de desmatamento não possuem relação direta com o crescimento populacional, mas sim a forma como é estabelecido o uso do solo. O desenvolvimento das atividades agropecuárias, que ao longo do tempo, passaram por um processo de mecanização, substituindo a mão de obra do trabalhador por máquinas equipadas com alta tecnologia, promoveu a evasão populacional, tendo em vista que esse latifúndio possui maior destaque diante do modelo minifundista, em que a forma de trabalho predominante é a agricultura familiar. Essa elevação do desmatamento nos últimos anos também pode ter sido causada pelo aumento do rebanho bovino no município e as expectativas de que a terra fosse valorizada devido à rota de escoamento da produção de soja no estado de Mato Grosso via porto de Miritituba, localizado em Itaituba/PA (Silva, 2019).

\section{Extrativismo}

Durante a década de 1980, a localidade denominada Progresso, começou a despertar o interesse de empresários e garimpeiros devido a descoberta de jazidas de ouro na região, levando-a ser considerada um importante polo econômico da região Norte. Diante disso, muitas pessoas migraram para a região causando um aumento populacional significativo e modificando a economia local (Araújo, 2015). Desse modo, como consequência de tais avanços, lideranças políticas decidiram municipalizar a região que passou a ser chamada de Novo Progresso, emancipando-a de Itaituba, com o intuito de aumentar suas riquezas promovendo o desenvolvimento da região (Ferreira, 2010). 
Segundo Araújo (2015), a partir da instalação de serrarias, a dinâmica de exploração madeireira na Amazônia aumentou de forma significativa, tendo como exemplo o povoado Moraes Almeida, localizado na estrada BR-163, no trecho inicial da estrada Transgarimpeira, que foi desenvolvido com base na exploração nativa e da indústria madeireira. Dos povoados presentes nas proximidades da BR-163, os que realizavam a exploração da indústria madeireira eram: Vila Alvorado com 4 serrarias, Trairão com 10, Moraes Almeida com 18, Castelo de Sonhos possuem 22 e Novo Progresso 27 serrarias (Araújo, 2015).

De acordo com Oliveira e Rodrigues (2017), o município de Novo Progresso é uma fronteira madeireira em desenvolvimento, sendo reconhecido como um pólo madeireiro de extrema importância para a Região Amazônica, apesar de possuir menos de 20 anos de atividade exploratória. A lenha é a única atividade do ramo extrativista que possui um valor significativo agregado, em função de produtores que também atuam como proprietários em áreas que possuem mais de 2500 ha (IBGE, 2006).

\section{Considerações Finais}

O emprego de produtos e técnicas de sensoriamento remoto associado aos recursos de SIG permitiu realizar a caracterização e análise dos aspectos florestais presentes na paisagem do município de Novo Progresso, por meio da avaliação quantitativa e qualitativa das classes analisadas.

A classe que ocupa a maior área no município de Novo Progresso é a de Floresta Densa, com cerca de 80\% da área total do município, mostrando que grande parte da área de floresta encontra-se preservada, mesmo a pecuária sendo uma das principais atividades dessa mesorregião. Em seguida, ocupa a classe de solo exposto com 13\%, posteriormente a classe de vegetação secundária apresentando 6,5\% e a classe de hidrografia correspondendo a $0,2 \%$ da área analisada.

Diante dos resultados obtidos foi possível concluir que as áreas que se encontram com o solo exposto não estão diretamente relacionadas com o crescimento populacional, mas sim a forma como é estabelecido o uso do solo, com base nas principais atividades desenvolvidas na região: Pecuária, Agricultura, Extrativismo Mineral, Extrativismo Vegetal e Estabelecimentos comerciais, considerando que a lógica produtiva ocorre de forma desordenada, não respeitando os critérios de desenvolvimento sustentável.

\section{Referências}

Alves, P. A., Amaral, S., Escada, M. I. S., \& Monteiro A. M. V. (2010). Explorando as relações entre a dinâmica demográfica, estrutura econômica e mudanças no uso e cobertura da terra no Sul do Pará: Lições para o Distrito Florestal Sustentável da BR-163. Rio Claro - MG. https://www.periodicos.rc.biblioteca.unesp.br/index.php/ageteo/article/view/4824/5186.

Araújo, L. S. M. (2015). Novo Progresso - PA: exemplo recente de ocupação na Amazônia. Resultados e Impactos. Monografia (Graduação) - Universidade de Brasília (UnB), 58 p. Brasília. https://bdm.unb.br/bitstream/10483/19284/1/2015_LaianeSantanaMenezesdeAraujo.pdf

Asta, A. P. D., Gavlak, A.A., Escada, M. I. S., Brigatti, N, \& Amaral, S. (2011). Núcleos de ocupação humana e usos da terra entre Santarém e Novo Progresso, ao longo da BR-163 (PA). São José dos Campos. http://mtc-m16d.sid.inpe.br/col/sid.inpe.br/mtcm19/2011/03.29.14.21/doc/publicacao.pdf?metadatarepository=\&mirror=iconet.com.br/banon/2006/11.26.21.31.

Becker, B. (2005). Geopolítica da Amazônia. São Paulo, Estudos Avançados, 19(53), 71-86. https://doi.org/10.1590/S0103-40142005000100005

Castro, E. (2005). Dinâmica socioeconômica e desmatamento na Amazônia, Novos Cadernos NEAE, 8(2). http://dx.doi.org/10.5801/ncn.v8i2.51

Costa, A. M. S., Bezerra, P. E. S., \& Oliveira, R. S. (2017). Mudanças no uso e ocupação da terra associadas a focos de calor na área de influência da Rodovia BR-163 (Cuiabá-Santarém). Revista Brasileira de Gestão Ambiental (Pombal - PB - Brasil), 11(1), 119-125. https://www.gvaa.com.br/revista/index.php/RBGA/article/view/4956/4264

Fearnside, P. M.(2002). Fogo e emissão de gases de efeito estufa dos ecossistemas florestais da Amazônia brasileira. Estudos Avançados 16 (44). https://doi.org/10.1590/S0103-40142002000100007

Fearnside, P. M.(2015). Hidrelétricas na Amazônia: impactos ambientais e sociais na tomada de decisões sobre grandes obras. Manaus: Editora do INPA, 1, 1-296. http://philip.inpa.gov.br/publ_livres/2015/Livro-Hidro-V1/Livro\%20Hidrel\%C3\%A9tricas\%20V.1.pdf 
Ferreira, B. O., Almeida, A. P., Leite, T. V. S., \& Costa, M. S. S.(2018). Uso e Ocupação do Solo do Município de Tailândia - Pa. Congresso Internacional Das Ciências Agrárias - Cointer Pdvagro. (3), 1-7.

Ferreira, J. C. V. (2003). O Pará e seus municípios. Belém: SEMEAR, Rede Celpa. 443-445.

Ferreira, J. O., Galbiati, C., Neves, S. M. A.S., \& Miranda, M. R. S. (2016). Produção de mel nos biomas Amazônia, Cerrado e Pantanal, em Mato Grosso, no período de 2002 a 2011. Desenvolvimento e Meio Ambiente, 39, 159-171. 10.5380/dma.v39i0.46505

Ferreira, S. B. (2010). Os impactos ambientais causados pela ação humana no atrativo turístico "praia da liberdade" no município de Novo Progresso-PA. Faculdade Opet de Curitiba-PR. https://docplayer.com.br/13436527-Os-impactos-ambientais-causados-pela-acao-humana-no-atrativo-turistico-praia-daliberdade-no-municipio-de-novo-progresso-pa.html

Gavlak, A. A., Escada, M. I. S., \& Monteiro, A. M. V. (2011). Dinâmica de padrões de mudança de uso e cobertura da terra na região do Distrito Florestal Sustentável da BR-163. Anais XV Simpósio Brasileiro de Sensoriamento Remoto - SBSR, Curitiba, PR, Brasil, INPE, 6152. http://marte.sid.inpe.br/col/dpi.inpe.br/marte/2011/06.27.12.54/doc/p1188.pdf

Gorelick, N, Hancher, M., Dixon, M., Ilyushchenko, S, Thau, D., \& Moore, R. (2017). Google Earth Engine: Planetary-scale geospatial analysis for everyone. Remote Sensing of Environment, v. 202, p. 18-27. https://doi.org/10.1016/j.rse.2017.06.031

IBGE (Instituto Brasileiro de Geografia e Estatística). (2006). SIDRA - Sistema IBGE de Recuperação Automática - Censo Agropecuário. http://www.sidra.ibge.gov.br/bda/default.asp?z=t\&o=1\&i=P.

IBGE (Instituto Brasileiro de Geografia e Estatística). (2019). SIDRA - Sistema IBGE de Recuperação Automática - Pesquisa da Pecuária Municipal. https://sidra.ibge.gov.br/pesquisa/ppm/quadros/brasil/2019.

IBGE (Instituto Brasileiro de Geografia e Estatística). (2019). SIDRA - Sistema IBGE de Recuperação Automática - Produção Agrícola Municipal. https://sidra.ibge.gov.br/pesquisa/pam/tabelas.

Junior, E. A. M., Silva, J. S. V., \& Oliveira, R. C. (2017). Geotecnologias no planejamento e ordenamento territorial. Anais do XVIII Simpósio Brasileiro de Sensoriamento Remoto - SBSR, INPE - Santos (SP), 4835-4842. https://ainfo.cnptia.embrapa.br/digital/bitstream/item/162042/1/MengatoJr-XVIIISBSR2017.pdf

Lameira, W. J M, Almeida A. S, \& Vieira, I. C. G. (2010). Síntese de ocupação em estradas não oficiais na Amazônia brasileira. Revista Brasileira de Cartografia, 01(62), 261-267. http://www.seer.ufu.br/index.php/revistabrasileiracartografia/article/view/43706/22970.

Margulis, S. (2003). Causas do desmatamento na Amazônia brasileira. The World Bank, Brasília. http://documents1.worldbank.org/curated/en/86771 1468743950302/pdf/277150PAPER0Po1az1nia0Brasileira111.pdf

Margarit, E. (2013) O processo de ocupação do espaço ao longo da BR 163: Uma leitura a partir do Planejamento Regional Estratégico da Amazônia durante o Governo Militar. Geografia em Questão - Projeto Saber. http://e-revista.unioeste.br/index.php/geoemquestao/article/view/6634.

Oliveira, A. H. M., \& Rodrigues, D. A. (2017). Análise exploratória da degradação florestal na Região de Novo Progresso (PA) e Sinop (MT) - Os Sistemas Degrad, Detex e Focos de Calor. Instituto Nacional de Pesquisas Espaciais (INPE). São José dos Campos - SP. http://wiki.dpi.inpe.br/lib/exe/fetch.php?media=ser300:trabalho_afonso_danilo.pdf.

Passos, M. M. (2017). BR-163, de Cuiabá a Santarém: o papel dos agentes e sujeitos no ordenamento do território e na implementação de políticas públicas. Ci. \& Tróp. Recife, 41(1), 139-164.

Pereira, A. G. C., David, É. C., Viana, J. A. S., Nazaré, J. V. S. P., Aleixo, L. R., Campinas, D. S. N., Hungria, L. C., \& Guedes, A. Da S. (2020). Uso de geotecnologias para avaliação do desempenho produtivo paraense na produção de mel, no período de 2008-2018. Brazilian Journal of Development, Curitiba, 6(5), 32087-32106.

Pereira, A. S., Shitsuka, D. M., Parreira F. J., \& Shitsuka R. (2018). Metodologia da pesquisa Científica. UFSM, NTE. https://repositorio.ufsm.br/bitstream/handle/1/15824/Lic_Computacao_Metodologia-Pesquisa-Cientifica.pdf?sequence=1

Rego, N., \& Freitas, R. M. (2015). Amazônia, representação e mídia. Revistafsa, 12(1), 107-120.

Rebello, F. K., \& Homma, A. K. O. (2017). História da colonização do Nordeste paraense: uma reflexão para o futuro da Amazônia. Belém, Pará: EDUFRA.

Rivero, S., Almeida, O., Ávila, S., \& Oliveira, W. (2009). Pecuária e desmatamento: uma análise das principais causas diretas do desmatamento na Amazônia. Nova Economia_Belo Horizonte_19 (1), 41-66. http://www.scielo.br/scielo.php?script=sci_arttext\&pid=S0103-63512009000100003.

Shuber, E, Souza, M, \& Moraes, S. (2015). Desenvolvimento Regional do Tapajós: Um Olhar Sob o Cenário Socioeconômico na Região de Integração do Tapajós. Revista de Estudos Sociais. 34(17), 93.

Silva, D. S.(2019). Trajetórias de uso e cobertura da terra no município de Novo Progresso, Pará. Trabalho de Conclusão de Curso (Graduação em Agronomia) - Universidade Federal Rural da Amazônia (UFRA), 34f. Belém. http://www.bdta.ufra.edu.br/jspui/bitstream/123456789/768/ 1/Trajet\%C3\%B3rias\%20de\%20uso\%20e\%20cobertura\%20da\%20terra\%20no\%20munic\%C3\%ADpio\%20de\%20Novo\%20Progresso-Par\%C3\%A1.pdf.

Xaud, M. R, \& Epiphanio, J. C. N. (2015). Análise da dinâmica das conversões de uso e cobertura da terra na região sudeste de Roraima - Amazônia. Agroambiente, 9(4), $465-475$. 